A C T A C H E M I C A S C A N D I N A V I C A 26 (1972) $2216-2222$

\title{
Inverse Drop Calorimeter for Enthalpy Determinations in the Range 300 to $1500 \mathrm{~K}$
}

\author{
FREDRIK GRøNVOLD
}

\author{
Kjemisk Institutt A, Universitetet i Oslo Blindern, Oslo 3, Norway
}

\begin{abstract}
The construction and operation of an inverse drop calorimeter for use in the temperature range 300 to $1500 \mathrm{~K}$ is described. The calorimeter is of the aneroid type and is operated with adiabatic shields. Calibration is performed electrically and compared with measurements on a standard sample of aluminum oxide. The estimated standard deviation for a single measurement on aluminum oxide is $0.21 \%$.
\end{abstract}

Tn the course of our thermodynamic investigations needs have arisen for 1 enthalpy determinations above $1000 \mathrm{~K}$, which is the limiting temperature of our adiabatic heat capacity calorimeter. ${ }^{1}$ The large amount of sample needed for that calorimeter $\left(50 \mathrm{~cm}^{3}\right)$ also in some cases prevents its use. A calorimeter for work with a few $\mathrm{cm}^{3}$ of sample up to $1500 \mathrm{~K}$ has therefore been constructed. It is of the drop-or rather the inverse drop-type, in which the heating furnace for the sample is placed below the calorimeter and the sample is hoisted into it for determination. This principle was chosen since it allows the sample to be transferred in a very reproducible way from furnace to calorimeter, and errors due to variations in transfer time are thus minimized. Jamming of the hot sample container in the calorimeter is also avoided. The quality of the temperature control equipment now commercially available makes aneroid calorimeters with adiabatic shield control especially attractive. The shield heater wires are usually distributed over the shield surface as evenly as possible. West and Ishihara ${ }^{2}$ have, however, successfully applied a heater system, where thin shields are fastened to a massive ring from which the heat is distributed. The present calorimeter was designed similarly in order to gain experience with the ring heater system.

The present paper contains a description of the calorimeter and some tests made on it with a standard sample of aluminum oxide. Results of measurements on metal halides in cooperation with the Institute of Inorganic Chemistry at the University of Trondheim will be reported in forthcoming papers. 


\section{EXPERIMENTAL}

\section{Calorimetric system}

A. Furnace. A vertical tube furnace serves as thermostat for the sample (Fig. I). The heater windings of Kanthal Al $(23 \mathrm{~m}, 1.15 \mathrm{~mm}$ diameter) are embedded in alundum coment (Morgan 931) together with alumina tubes for a platinum resistance thermometer and a Pt-90Pt10Rh thermocouple. The alundum cement tube is mounted in a watercooled casing, insulated with diatomaceous earth. An exchangeable Pythagoras tube (70 $\mathrm{cm}$ long, $27 \mathrm{~mm}$ i.d.) is mounted inside the heater tube and the sample container is: suspended in the middle of this tube.

The temperature of the furnace is controlled by a proportional controller (Sirect Mark 2) with a $9 \Omega$ platinum resistance thermometer as sensing element and a $30 \mathrm{~A}$ silicon thyristor as power source. The controller is claimed to keep the temperature of a $1.5 \mathrm{kVA}$ furnace constant to better than $0.2 \mathrm{~K}$ at $1300 \mathrm{~K}$ from an unstabilized mains. supply. The temperature of the sample is measured by means of a calibrated Pt-90Pt10Rh thermocouple, located $1-3 \mathrm{~mm}$ below the bottom of the sample container, a microvolt potentiometer (O. Wolff) and a null detector (Keithley Model 149). In order to obtain a reasonably constant temperature zone in the furmace, the pitch of the windings was: reduced from $4 \mathrm{~mm}$ over the central portion to $2.5 \mathrm{~mm}$ at the ends. In addition, two taps were provided so that the current through the central section and each of the end sections could be individually controlled. After some experimentation a constant tem. perature zone within $\pm 0.7 \mathrm{~K}$ over $15 \mathrm{~cm}$ at temperatures in the range 800 to $1300 \mathrm{~K}$ was attained. The radial temperature gradient from the center to the Pythagoras tube. wall was about $1.5 \mathrm{~K}$. The furnace has $15 \mathrm{~cm}$ of firebrick insulation at the lower end with a central hole for the thermocouple. At the upper end the furnace is closed by a. water-cooled brass shutter with a $0.5 \mathrm{~mm}$ slit for the suspension wire.

Fig. 1. Sample thermostat. Calorimeter entrance port (a), 75Pt25Ir suspension wire (b), water-cooled brass shutter (c), watercooled casing (d), alundum cement tube (e), Kanthal A heating element (f), Pythagoras tube (g), sample container (h), measuring Pt-90Pt10Rh thermocouple (i).

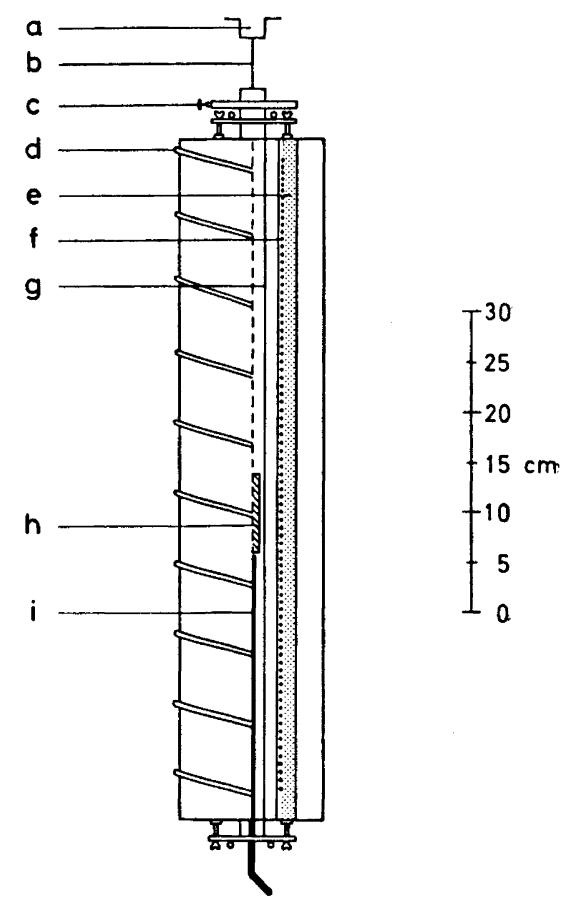

Acta Chem. Scand. 26 (1972) No. 6 


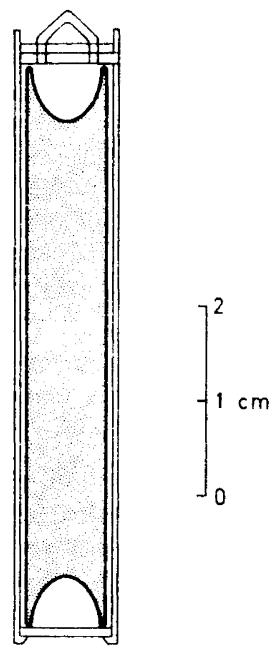

Fig. 2. Sample container. Outer tube of 90PtloRh, inner tube of Pt.

B. Sample container. Since the calorimeter was to be constructed for enthalpy determinations on fluorides, sulfides, etc., it was found advantageous to keep the sample in an inner container (platinum for fluorides, quartz for sulfides) and to put this into an outer container of 90Pt10Rh (Fig. 2). For less reactive substances no inner container is necessary. The inner platinum tube for use with the fluorides is $59 \mathrm{~mm}$ long, $8 \mathrm{~mm}$ inside diameter, and has a wall thickness of $0.2 \mathrm{~mm}$. It is closed by arc-welding a small platinum cup to the wall of the tube under 1 atm of argon gas. The outer container has a closing mechanism at the upper end which allows easy exchange of sample and empty capsule. It is suspended by a $0.25 \mathrm{~mm}$ diameter $75 \mathrm{Pt} 25 \mathrm{Ir}$ wire.

$C$. Hoisting mechanism. In the present instrument the sample is hoisted from the furnace into the calorimeter instead of being dropped into it. This is accomplished by connecting a weight to the suspension wire. The weight is shaped in form of a piston and is allowed to fall in a polished brass tube. Holes of decreasing diameter are bored down the wall of the tube for air-braking purpose. The hoist-time is adjusted to 1.0 sec for the $42 \mathrm{~cm}$ travel by a suitable excess mass of the piston compared to the sample container. Microswitch contacts are provided at top and bottom of the fall-tube for automatic opening and closing of the gates in the calorimeter.

D. Calorimeter. The sample receiver or calorimeter is of the aneroid type and surrounded by shields (Fig. 3). Silver was chosen as construction material since the temperature of the calorimeter ought to be adjustable up to at least $800 \mathrm{~K}$ for studying samples which do not come to equilibrium on rapid cooling to lower temperatures. The central silver block, which is $8 \mathrm{~cm}$ in diameter and $15 \mathrm{~cm}$ long, weighs about $5 \mathrm{~kg}$. It has an axial hole for the sample container, tapering from 15 to $12 \mathrm{~mm}$ in diameter, one well for a platinum resistance thermometer, and one for a quartz thermometer. Slots are machined in the silver to slow down the heat wave through the block when the sample container is introduced. Around the middle of the silver body a silver ring is fastened which serves as support for two concentric "hats" around the top and bottom halves of the calorim ter. They are made of $0.5 \mathrm{~mm}$ silver sheet.

Outside the calorimeter proper are located two shield systems of similar construction to the one that covers the calorimeter block. These systems, termed shield I and II, contain heater elements of Thermocoax in a middle ring of silver. In addition there is an outer shield III of $5 \mathrm{~mm}$ aluminum, also with enclosed heating element. The latter is not in use when the calorimeter temperature stays below $350 \mathrm{~K}$. All three shields have axial holes. Those in the upper half are for the hoisting wire and have a diameter of $1.5 \mathrm{~mm}$. The holes in the bottom half are $12 \mathrm{~mm}$ in diameter and allow passage of the sample container. They can be closed by silver plates, two in the calorimeter, and one

Acta Chem. Scand. 26 (1972) No. 6 


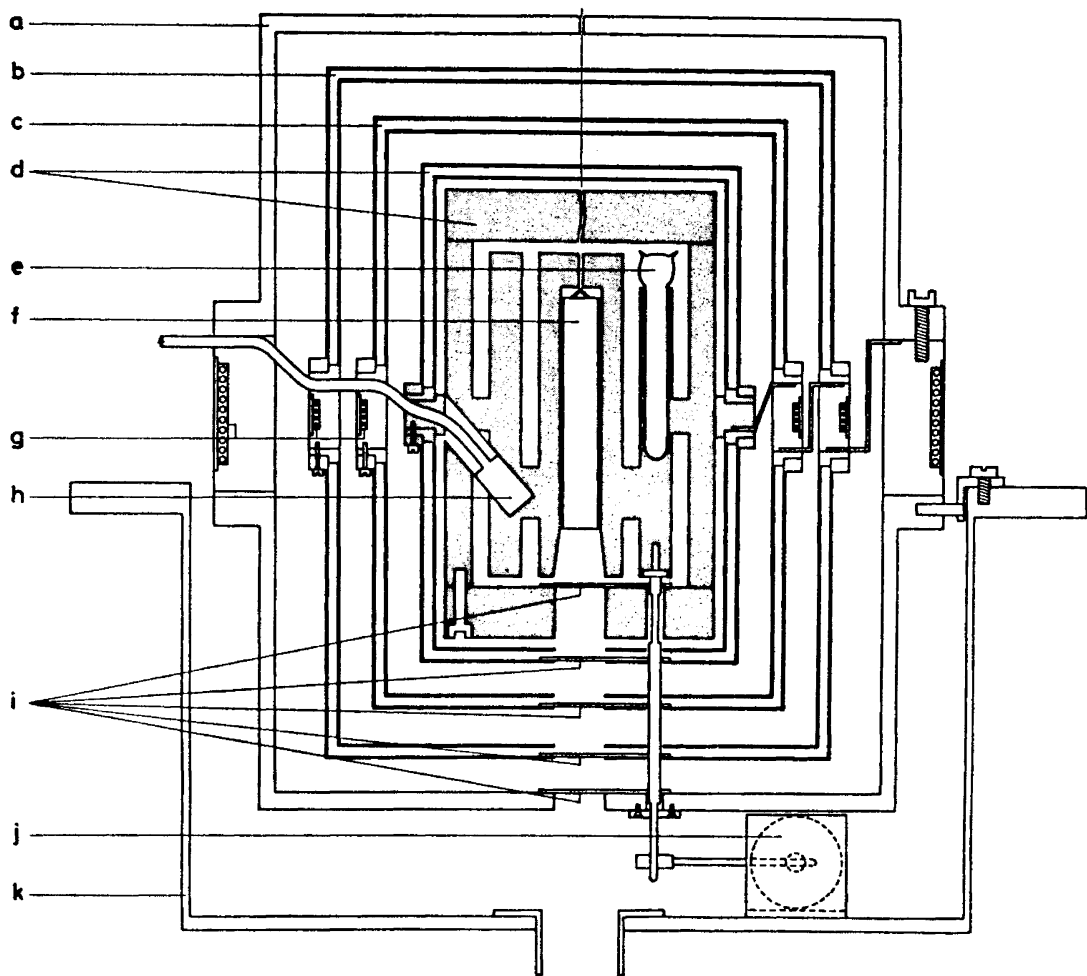

Fig. 3. Calorimeter. Massive aluminum shield III (a), outer double-walled silver shield II (b), inner double-walled silver shield I (c), calorimeter block with silver covers (d), Pt resistance thermometer (e), sample container (f), shield ring heaters (g), quartz thermometer $(\mathrm{h})$, silver shutters $(\mathrm{i})$, electromagnets $(\mathrm{j})$, steel can $(\mathrm{k})$.

in each of the three shields. The silver plates have a narrow slit from side to center for the suspension wire. The magnetically operated shutter is placed in the steel outer can which rests in a frame together with the furnace. The aluminum shield is located within the steel can by means of steering pins, while the inner shields and the calorimeter are supported by stainless steel strips.

The temperature of the calorimeter is usually measured by means of a quartz thermometer (Hewlett-Packard Model 2801A) and the results recorded by a printer (Beckman Model 1453). For calibration purposes and work above $500 \mathrm{~K}$ a platinum resistance thermometer (Leeds and Northrup Model 8164) is used in connection with a Mueller bridge.

The temperature of shield $\mathrm{I}$ is made to follow the temperature of the calorimeter by means of a shield control system as indicated in Fig. 4. One copper-constantan thermocouple is located in the calorimeter ring and the other in the shield heater ring. The potential difference is amplified by a nano-voltmeter (Astrodata Model 121 RZ) and recorded. The control slidewire on the recorder (Speedomax $H$ ) is connected to a current adjusting control unit (Leeds and Northrup Model 10877), with proportional, integral and derivative action and an output singal of $0-5 \mathrm{~mA}$ over $3000 \Omega$. This signal is amplified by a thyristor unit to give $0-2 \mathrm{~A}$ in the $4 \Omega$ Thermocoax heating element. The zero-point of the recorder can be suitably offset to provide approximately zero drift of the calorimeter by means of a bucking potential from a Zener diode, and a potential divider with a ten-turn Helipot.

Acta Chem. Scand. 26 (1972) No. 6 


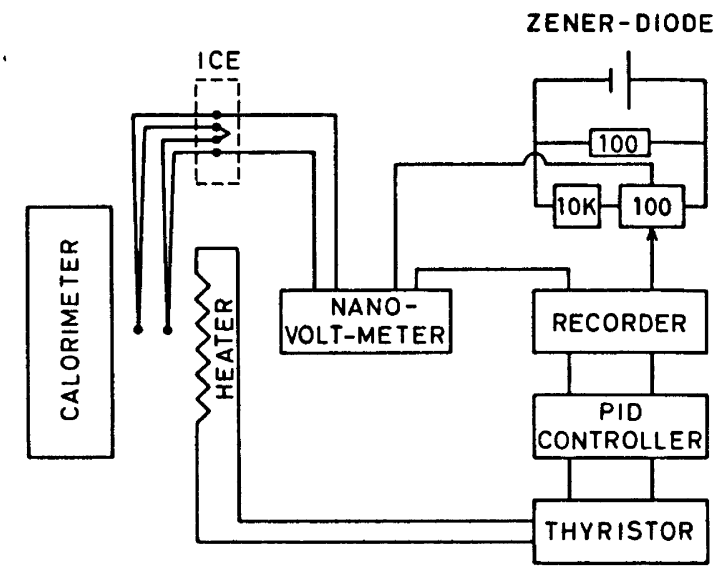

Fig. 4. Shield control system.

The temperature of shield II is governed by that of shield I in a similar manner, but is kept about $4 \mathrm{~K}$ lower in temperature. The thermocouples used here are of Pt-90Pt10Rh in connection with a null detector (Leeds and Northrup Model 9834-2). The output signal goes directly to the current adjusting control unit without being recorded, and then to the thyristor and heating element.

\section{Calibration}

The calorimeter is calibrated electrically by means of a constant current source (Fluke Model $382 \mathrm{~A}$ ) and an integrating voltmeter (Hewlett-Packard Model 2401C). The temperature of the calorimeter is raised about $5 \mathrm{~K}$ above room temperature and the zero drift is adjusted to be less than $0.001 \mathrm{~K}$ between two consecutive readings, about 100 sec apart. A measured amount of electrical energy, varying from about 1 to $35 \mathrm{~kJ}$ is then dissipated in the calorimeter and the approach to a new equilibrium temperature recorded. In order to compensate for changing drift rate as result of increasing calorimeter temperature the zero-point of the shield control units is judiciously shifted with temperature. The apparent mean heat capacity of the calorimetric system is derived by standard procedures ${ }^{3}$ and the results can be expressed as over the range 300 to $350 \mathrm{~K}$

$$
C=1324.9+0.489(T / \mathrm{K}) \mathrm{J} \mathrm{K}^{-1}
$$

with a standard deviation of $0.05 \%$.

\section{Method of operation}

In the actual enthalpy measurements on aluminum oxide to test out the calorimeter, one empty platinum capsule sealed under argon and one filled with sample have been used. The sample container with the empty capsule is first lowered into the furnace. After about $30 \mathrm{~min}$ equilibrium is usually established, as indicated by a temperature constancy of $0.1 \mathrm{~K}$ over a 5 min interval. The capsule is then hoisted into the calorimeter and the temperature of the calorimeter recorded as a function of time. Steady state conditions are usually obtained after 10 to $15 \mathrm{~min}$ and the measurements are continued for ten more minutes. A capsule filled with sample (4.4133 $\mathrm{g} \mathrm{Al}_{2} \mathrm{O}_{2}$ ) is then exchanged for the empty one. Two series of measurements are generally carried out on the sample 
without changing the furnace setting, and subsequently the empty capsule is measured again.

The observed data are transferred to punch cards together with values of mass, molecular weight, and measured or estimated heat capacity of the sample over the region 300 to $350 \mathrm{~K}$, the mass of sample capsule, empty capsule, and outer container. In the computer program the steady state criterion is that the change in temperature drift over four consecutive $100 \mathrm{sec}$ intervals is less than $0.0002 \mathrm{~K}$. Drift corrections are then carried out and the enthalpy change over the temperature range in question is calculated. The enthalpy increment of the empty sample container is calculated on the basis of enthalpy equations for the actual materials and compared with the observed values. The program subtracts the calculated enthalpy of the empty sample container and corrects the molar enthalpy increments of the compound to the reference temperature $298.15 \mathrm{~K}$. When systematic deviations exceeding the estimated limits of error occur for the empty capsule, the actually measured values are preferred.

\section{RESULTS}

The high temperature enthalpy of an $\alpha$-aluminum oxide sample, prepared by the U.S. National Bureau of Standards at request of the Fourth Calorimetry Conference (in 1948) was measured at different temperatures in the range 872 to $1271 \mathrm{~K}$. The enthalpy of the sample represented about $50 \%$ of the total. The results are presented in Table 1 for $1 \mathrm{~mol}$ of $\alpha-\mathrm{Al}_{2} \mathrm{O}_{3}$, corresponding to $101.96 \mathrm{~g}$. Temperatures are given in terms of the International Practical Temperature Scale of 1968.

Table 1. Experimental data for aluminum oxide. ${ }^{a}$

\begin{tabular}{|c|c|c|c|c|}
\hline$T / \mathbf{K}$ & $\begin{array}{c}\text { Order of } \\
\text { expt. }\end{array}$ & $\begin{array}{l}\left(H_{\mathrm{T}}-\right. \\
\text { obs. }\end{array}$ & $\begin{array}{l}{ }^{-1} \mathrm{~mol} \\
\text { calc. }\end{array}$ & $\begin{array}{c}\text { Dev. } \\
\%\end{array}$ \\
\hline \multirow[t]{3}{*}{872.0} & 1 & 62404 & 62174 & 0.36 \\
\hline & & 62191 & & 0.03 \\
\hline & & 62220 & & 0.07 \\
\hline \multirow[t]{2}{*}{901.7} & 5 & 65842 & 65806 & 0.05 \\
\hline & & 65596 & & -0.32 \\
\hline \multirow{2}{*}{968.9} & 7 & 74350 & 74120 & 0.31 \\
\hline & & 74181 & & 0.08 \\
\hline \multirow[t]{2}{*}{973.3} & 2 & $(72317)$ & 74684 & - \\
\hline & & 74969 & & 0.38 \\
\hline 1027.7 & 6 & 81601 & 81504 & 0.11 \\
\hline \multirow[t]{2}{*}{1075.8} & 3 & 87551 & 87487 & 0.07 \\
\hline & & 87697 & & 0.23 \\
\hline 1096.4 & 9 & 90333 & 90144 & 0.20 \\
\hline \multirow[t]{2}{*}{1124.3} & 8 & 93701 & 93671 & 0.03 \\
\hline & 4 & $\begin{array}{c}(92814) \\
99968\end{array}$ & 99998 & $-0 . \overline{03}$ \\
\hline 1174.6 & & 100313 & & 0.31 \\
\hline \multirow{3}{*}{1270.7} & 10 & 112313 & 112261 & 0.04 \\
\hline & & 112131 & & -0.12 \\
\hline & & 112488 & & 0.20 \\
\hline
\end{tabular}

${ }^{a} \alpha-\mathrm{Al}_{2} \mathrm{O}_{3}, \mathrm{l} \mathrm{mol} \stackrel{\wedge}{=} 101.96 \mathrm{~g}$

Acta Chem. Scand. 26 (1972) No. 6 
The observed enthalpy increment values are compared with those reported by Furukawa et al. ${ }^{4}$ after correction of the temperature scale. ${ }^{5}$ The estimated standard deviation for a single measurement on aluminum oxide is $0.21 \%$. The accuracy in the determinations is taken to be $0.10 \%$, i.e. two times the estimated standard deviation of the mean. This is considered very satisfactory for an aneroid system operating in air and with an inner container for confinement of the substance.

Results obtained for alkali cryolites will be reported in a forthcoming paper. ${ }^{6}$

Acknowledgements. A grant for equipment by Norges almenvitenskapelige forskningsråd to Professor Kai Grjotheim and the author is gratefully acknowledged. The assistance of Sverre Nordvik and the firm K. A. Rasmussen in manufacturing some of the silver parts for the calorimeter is appreciated. The major constructional work was carried out in the machine shop of the institute under the direction of Bjørn Dalbakk and Amund Helgesen. The assistance of Birgit Jenssen Holm, Niels Jørgen Kveseth and Bjørn Lyng Nielsen in the experimental work is thankfully recognized.

\section{REFERENCES}

1. Grønvold, F. Acta Chem. Scand. 21 (1967) 1695.

2. West, E. D. and Ishihara, S. Advan. Thermophys. Prop. Extreme Temp. Pressures, ASME N.Y. 1965 , p. 146.

3. McCullough, J. P. and Scott, D. W., Eds., Experimental Thermodynamics, Vol. 1, Calorimetry of Non-reacting Systems, Butterworths, London 1968.

4. Furukawa, G. T., Douglas, T. B., McCoskev, R. E. and Ginnings, D. C. J. Res. Natl. Bur. Std. 57 (1956) 67.

5. The International Practical Temperature Scale of 1968, Metrologia 5 (1969) 35.

6. Jenssen Holm, B. and Grønvold, F. Acta Chem. Scand. To be published.

Received November 5, 1971. 